\title{
Current noninvasive modalities in Crohn's disease monitoring
}

\author{
loannis V. Mitselos ${ }^{a}$, Fotios S. Fousekis ${ }^{b}$, Charikleia Lamouri, ${ }^{b}$ Konstantinos H. Katsanos ${ }^{b}$, \\ Dimitrios K. Christodoulou ${ }^{b}$
}

General Hospital of Ioannina; School of Health Sciences, University Hospital of Ioannina, Greece

\begin{abstract}
Crohn's disease $(\mathrm{CD})$ is characterized by a remitting and relapsing course. Longstanding active CD may result in accumulating intestinal damage and disease-related complications. In contrast, mucosal healing is associated with significant improvement in the health-related quality of life, longer periods of disease remission and lower risk of disease progression, complications, hospitalizations, intestinal surgeries, as well as a lower risk of developing colorectal cancer. Mucosal healing, the new treatment endpoint in $\mathrm{CD}$, made necessary the development of noninvasive, accurate, objective and reliable tools for the evaluation of $\mathrm{CD}$ activity. Ileocolonoscopy with biopsies remains the reference standard method for the evaluation of the colonic and terminal ileal mucosa. However, it is an invasive procedure with a low risk of complications, allowing the investigation of only a small part of the small bowel mucosa without being able to assess transmural inflammation. These disadvantages limit its role in the frequent follow up of CD patients. In this review, we present the currently available biomarkers and imaging modalities for the noninvasive assessment of CD activity.
\end{abstract}

Keywords Crohn's disease, monitoring, disease activity

Ann Gastroenterol 2021; 34 (1): 1-11

\section{Introduction}

Until now, there has been no single diagnostic test able to interpret symptoms and signs, evaluate treatment efficacy, guide patient management, predict the clinical course, disease behavior and the development of disease-related complications in patients with Crohn's disease (CD). Thus, patient management is based on the assessment of disease activity, location, extent, and the presence of complications or extraintestinal manifestations [1].

Mucosal healing is becoming the treatment goal and therapeutic endpoint in $\mathrm{CD}$, partially replacing the role of clinical and biochemical markers that, in a significant proportion of patients, were demonstrated to underestimate disease activity and correlate poorly with endoscopic findings [2-4]. In detail, mucosal healing is a recently introduced complex concept and, despite the lack of an accepted definition, it could be defined

Department of a Gastroenterology, General Hospital of Ioannina (Ioannis V. Mitselos); 'Gastroenterology, School of Health Sciences, University Hospital of Ioannina, Faculty of Medicine, University of Ioannina (Fotios S. Fousekis, Charikleia Lamouri, Konstantinos H. Katsanos, Dimitrios K. Christodoulou), Greece

\section{Conflict of Interest: None}

Correspondence to: Dimitrios K. Christodoulou, MD, PhD, Professor of Gastroenterology, Department of Gastroenterology, School of Health Sciences, University Hospital of Ioannina, Faculty of Medicine, University of Ioannina, PO Box 1186, Ioannina, 45110, Greece, e-mail: dchristo@uoi.gr

Received 3 November 2020; accepted 16 April 2021; published online 2 July 2021

DOI: https://doi.org/10.20524/aog.2021.0648 as the disappearance of inflammatory endoscopic lesions [5]. Mucosal healing is associated with significant improvement in health-related quality of life, a lower risk of disease progression, as well as a lower risk of colorectal cancer $[4,6,7]$.

Endoscopy and cross-sectional imaging modalities are invaluable tools in CD monitoring [8]. Upper gastrointestinal $\mathrm{CD}$ involvement is optimally evaluated with upper gastrointestinal endoscopy, whereas ileocolonoscopy, despite its inability to determine transmural inflammation, allows the direct visualization of the inflamed intestinal mucosa, tissue sampling, and malignancy screening [9]. Moreover, the development of endoscopic indices-CD endoscopic index of severity (CDEIS), Simple Endoscopic Score for CD (SES$\mathrm{CD}$ ), Rutgeerts score-has enabled the objective and reliable quantification of mucosal inflammation [10-12].

On the other hand, there are several considerations regarding the role of ileocolonoscopy in $\mathrm{CD}$ monitoring: a) the inflammatory insult in $\mathrm{CD}$ is transmural; b) whilst the small bowel is predominantly affected, as $70 \%$ of patients have ileal or ileocolonic disease, conventional endoscopes enable the visualization of only a short segment of the terminal ileum mucosa; c) in a small proportion of patients the terminal ileum cannot be reached or is inaccessible due to ileocecal valve stricturing; d) the inflamed mucosa is characterized by a patchy distribution which may result in a false negative endoscopic study; e) patients may feel uncomfortable with the colonoscopy procedure, as it requires bowel preparation; and lastly, f) it carries a low risk of complications $[9,13-15]$. For all these reasons, ileocolonoscopy is less than ideal for the frequent follow up of CD patients.

The technologic innovation of capsule endoscopy allowed the minimally invasive evaluation of the entire small and 
large bowel mucosa, with a superior diagnostic performance in the detection of proximal and mild small bowel disease in comparison to other modalities [16,17]. However, capsule endoscopy does not allow the acquisition of tissue samples, it carries a small but considerable risk of procedure-related complications (e.g. capsule retention, intestinal perforation), it requires bowel preparation and it is contraindicated in selected cases [17]. Moreover, it is a time-consuming procedure, a small but considerable proportion of patients will have an incomplete examination, whilst it only allows the evaluation of the intestinal mucosa, without being able to provide information regarding transmural inflammation, disease behavior (stricturing or penetrating disease) and disease-related complications $[17,18]$, the assessment of which is largely based on the use of crosssectional imaging modalities [19].

Due to the relapsing and remitting clinical course of CD, the development of noninvasive, accurate, objective and reliable diagnostic modalities for the evaluation of mucosal inflammation would allow prompt identification of disease exacerbation, especially in the pediatric and adolescent population, where there are concerns over the use of potentially harmful procedures and sedation. As landmark studies have demonstrated that treatment decisions based on a tight control monitoring strategy with noninvasive biomarkers lead to improvement in endoscopic and clinical outcomes [20], the aim of this review was to present and analyze the currently available tools for the noninvasive evaluation of $\mathrm{CD}$ activity.

\section{Materials and methods}

A thorough search was performed in PubMed from 2000 up to June 2020, to identify articles that describe biomarkers and other diagnostic methods for the evaluation of $\mathrm{CD}$ activity. The search for relevant studies was performed using the follow search string: ("Crohn's disease") AND ("assessment" OR "evaluation" OR "monitoring" OR "follow-up" OR "follow up") AND ("mucosal inflammation" OR “inflammation" $O R$ "activity" OR "disease activity"). The search was supplemented with the addition of suitable articles cited in the reference lists of the included studies. A list of the key studies regarding the diagnostic performance of the currently available and emerging modalities in CD activity assessment can be found in Table 1 .

\section{Biomarkers}

The discovery of a noninvasive marker that could reflect the complex condition of mucosal healing is really difficult. Nevertheless, a significant amount of research has been dedicated to identifying a minimally invasive, low cost, easy to determine, objective and reproducible biomarker that enables disease prognosis and the assessment of treatment response. The most used and most studied biomarkers in CD monitoring are C-reactive protein (CRP) and fecal calprotectin (FC). Among their advantages are availability and low cost.
CRP is an acute phase protein produced in the liver in response to circulating inflammatory cytokines. According to the results of a recent meta-analysis, despite the low sensitivity (49\%), a CRP level $>5 \mathrm{mg} / \mathrm{dL}$ was demonstrated to be highly specific (>90\%), with an area under the curve (AUC) of 0.72 , in the discrimination of endoscopic activity [21]. However, its use in the assessment of CD activity has several limitations: any inflammatory condition may result in CRP elevation, its production is related to the patient's characteristics, whilst the patient's genetic profile affects the CRP level, with up to $25 \%$ of CD patients being unable to produce significant CRP levels despite endoscopic activity [22,23]. Thus, although further diagnostic investigation is warranted in patients with abnormal CRP, its interpretation in CD monitoring should be made cautiously.

FC

FC, a protein released by activated neutrophils in the intestinal chyme in response to intestinal inflammation, can be quantified and is the most studied fecal biomarker of inflammation. It resists proteolysis for up to 7 days at room temperature and can be measured from a small fecal sample [24]. A cutoff point of $<250 \mu \mathrm{g} / \mathrm{g}$ is a useful surrogate marker for mucosal healing in CD [25]. In detail, FC sensitivity and specificity in the prediction of endoscopic activity is depended on the cutoff level used: a cutoff value between $50-100 \mu \mathrm{g} / \mathrm{g}$ results in high sensitivity and specificity [26,27], with FC levels below $50 \mu \mathrm{g} / \mathrm{g}$ practically eliminating the possibility of mucosal inflammation.

FC was shown to have $87 \%, 67 \%$ and 0.85 pooled sensitivity, specificity and AUC, respectively, in the diagnosis of endoscopic activity [21].

Nevertheless, FC is unable to determine the cause of inflammation, whereas abnormal levels can be associated with gastrointestinal neoplasms and microbial gastrointestinal infections. Finally, FC was demonstrated to perform better in patients with colonic mucosa inflammation [28], which may limit its use in patients with small bowel CD.

\section{Other biomarkers}

Of the numerous biomarkers [29-67] continually being discovered (Table 2), some are attracting great interest due to their high diagnostic accuracy and ease of use. Below we present the most promising biomarkers based on their diagnostic performance, availability and ease of use.

\section{Fecal hemoglobin}

The detection of fecal hemoglobin, via ELISA, fecal occult blood testing (FOBT), and fecal immunochemical testing (FIT), has been proposed as an alternative biomarker for the 
Table 1 Key studies regarding the diagnostic performance of the currently available and emerging modalities in the assessment of CD activity

\begin{tabular}{|c|c|c|c|c|c|c|c|}
\hline Diagnostic method & Study [Ref.] & SENS & SPEC & PPV & NPV & AUC & $\begin{array}{l}\text { Correlation with } \\
\text { endoscopic findings }\end{array}$ \\
\hline \multicolumn{8}{|l|}{ Serum biomarkers } \\
\hline CRP & Mosli MH, 2015 [21] & $49 \%$ & $92 \%$ & NA & NA & 0.72 & NA \\
\hline Serum BAFF & Zhang P, 2016 [52] & $59 \%$ & $93 \%$ & NA & NA & 0.79 & NA \\
\hline Serum amyloid A & Ishihara S, 2018 [29] & $68 \%$ & $83 \%$ & NA & NA & 0.77 & $r=0.64$ \\
\hline Serum amyloid A & Yarur AJ, 2017 [30] & $64 \%$ & $95 \%$ & NA & NA & $0.77-0.81$ & NA \\
\hline \multicolumn{8}{|l|}{ Fecal biomarkers } \\
\hline Fecal calprotectin & Mosli MH, 2015 [21] & $87 \%$ & $67 \%$ & NA & NA & 0.85 & NA \\
\hline Fecal BAFF & Xie C, 2019 [51] & $85 \%$ & $91 \%$ & $84 \%$ & $92 \%$ & NA & NA \\
\hline Fecal BAFF & Fu Y, 2017 [48] & $84 \%$ & $100 \%$ & $100 \%$ & $64 \%$ & NA & $\mathrm{r}=0.58$ \\
\hline FIT & Mooiweer E, 2014 [50] & $73 \%$ & $79 \%$ & NA & NA & 0.89 & $\mathrm{r}=0.44$ \\
\hline FOBT & Fu Y, $2017[48]$ & $41 \%$ & $93 \%$ & $90 \%$ & $49 \%$ & 0.79 & NA \\
\hline \multicolumn{8}{|l|}{ Composite biomarker tests } \\
\hline $\begin{array}{l}\text { EHI index (early-stage } \\
\text { CD) }\end{array}$ & D’Haens G, 2019 [76] & $97.1 \%$ & $69.0 \%$ & NA & NA & 0.88 & NA \\
\hline $\begin{array}{l}\text { EHI index (moderate-to- } \\
\text { severe } \mathrm{CD} \text { ) }\end{array}$ & D’Haens G, 2019 [76] & $83.2 \%$ & $36.6 \%$ & NA & NA & 0.62 & NA \\
\hline $\begin{array}{l}\text { Combination of } \\
\text { Eotaxin-1, SAA, IL-6, } \\
\text { IL-8 }\end{array}$ & Bourgonje AR, 2019 [75] & $90.7 \%$ & $68.4 \%$ & $86.7 \%$ & NA & 0.84 & NA \\
\hline \multicolumn{8}{|l|}{ Computed tomography } \\
\hline CTE & Horsthuis K, 2008 [81] & $84.3 \%$ & $95.1 \%$ & NA & NA & NA & $\mathrm{r}=0.70$ \\
\hline Low-dose CTE & Rosenfeld G, 2018 [98] & $85-94 \%$ & $84-97 \%$ & NA & NA & NA & NA \\
\hline Dual-energy CT & De Kock I, 2019 [100] & NA & NA & NA & NA & 0.96 & NA \\
\hline Dual-energy CT & Kim YS, 2018 [99] & NA & NA & NA & NA & NA & $\mathrm{r}=0.74$ \\
\hline \multicolumn{8}{|l|}{$\begin{array}{l}\text { Magnetic resonance } \\
\text { imaging }\end{array}$} \\
\hline MaRIA index & Buisson A, 2017 [106] & $73.9 \%$ & $82.1 \%$ & NA & $82.1 \%$ & NA & NA \\
\hline MaRIA index & Rimola J, 2009 [107] & NA & NA & NA & NA & 0.89 & $\mathrm{r}=0.82$ \\
\hline Clermont score & Buisson A, 2017 [106] & $74 \%$ & $81.3 \%$ & NA & $82.4 \%$ & NA & NA \\
\hline $\begin{array}{l}\text { Diffusion-weighted } \\
\text { imaging MRI }\end{array}$ & $\begin{array}{l}\text { Stanescu-Siegmund N, } \\
2017 \text { [113] }\end{array}$ & $97.4 \%$ & $99.2 \%$ & NA & NA & NA & NA \\
\hline \multicolumn{8}{|l|}{ Ultrasound } \\
\hline SICUS & Pallotta N, 2005 [117] & $100 \%$ & $98 \%$ & NA & NA & NA & NA \\
\hline CEUS & De Franco A, 2012 [127] & $86-97 \%$ & $83 \%$ & NA & NA & NA & NA \\
\hline
\end{tabular}

CD, Crohn's disease; SENS, sensitivity; SPEC, specificity; PPV, positive predictive value; NPV, negative predictive value; $A U C$, area under the curve; $C R P, C$-reactive protein; FIT, fecal immunochemical test; FOBT, fecal occult blood test; BAFF, B-cell activating factor; EHI, endoscopic healing index; IL, interleukin; CT, computed tomography; MRI, magnetic resonance imaging; SICUS, small intestine contrast ultrasonography; CEUS, contrast-enhanced ultrasound; NA, not available

investigation of mucosal inflammation [48-50]. In particular, FIT is a low cost, easy to perform and widely available modality, allowing the objective and reliable evaluation of disease activity through the quantification of hemoglobin concentration in the feces, demonstrated to have $74 \%$ sensitivity, $84 \%$ specificity, $72 \%$ positive predictive value (PPV), $84 \%$ negative predictive value (NPV), and an AUC of 0.81 [50]. Although its diagnostic accuracy was shown to be comparable to that of FC, it has been shown to perform better in patients with colonic disease [68]. Despite the limited data regarding its role in CD patients, FOBT was demonstrated to predict mucosal inflammation with $65 \%$ sensitivity, 93\% specificity, 97\% PPV and 43\% NPV [48].

Nevertheless, physicians should be aware that fecal occult blood tests may produce false positive results in patients on nonsteroidal anti-inflammatory drugs, aspirin and red meat consumers, or false negative results in patients who consume high levels of vitamin C.

\section{B cell-activating factor (BAFF)}

Another potential biomarker is fecal BAFF. BAFF is responsible for the formation and homeostasis of B cells, as well as the survival of autoimmune cells $[69,70]$. In addition, BAFF overexpression is associated with the development of autoimmune diseases [71]. Recently, it was demonstrated that, in patients with relevant gastrointestinal symptoms, fecal BAFF can be highly sensitive (84-85\%) and highly specific $(>90 \%)$ in the discrimination among patients with inflammatory bowel disease (IBD), those with irritable bowel syndrome, and healthy controls. Although the sensitivity of serum BAFF in the diagnosis of mucosal inflammation was demonstrated to be moderate (59\%), it shows excellent specificity $(93 \%)[48,51,52]$.

It should be noted that fecal BAFF measurement should be made under the appropriate clinical context, as abnormal levels 
Table 2 List of studied biomarkers for the assessment of Crohn's disease activity

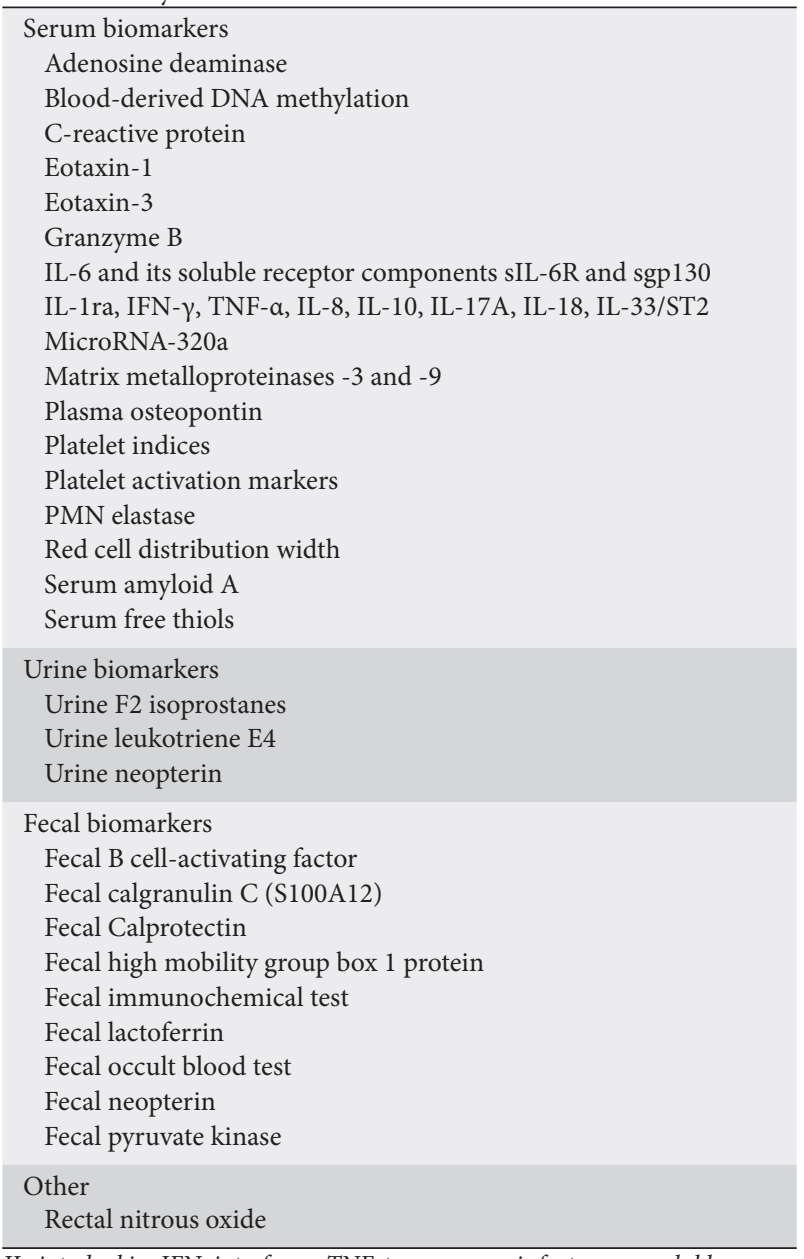

IL, interleukin; IFN, interferon; TNF, tumor necrosis factor; sgp, soluble glycoprotein

of fecal BAFF may be found not only in IBD, but also in other conditions, such as gastrointestinal neoplasms [51].

\section{Serum amyloid A (SAA)}

Recently, 2 studies proposed SAA as a significant surrogate marker for the evaluation of CD activity. SAA is an acute phase protein, shown to correlate closely with endoscopic activity $(\mathrm{r}=0.64, \mathrm{P}<0.01)$ [29], with an AUC between 0.77-0.81 [29,30] for the classification of macroscopic and microscopic mucosal inflammation.

\section{MicroRNA-320a}

MicroRNAs are small non-coding RNA molecules responsible for RNA silencing and post-transcriptional regulation of gene expression [72]. In colitic mice, microRNA$320 \mathrm{a}$ levels were demonstrated to correlate with disease activity [73], confirmed in a recent preliminary study with CD and UC patients [74]. In detail, microRNA-320a showed strong correlation with the SES-CD score in CD patients $\left(r^{2}=0.76\right.$; $\mathrm{P}<0.001)$.

\section{Composite biomarker tests}

In a recent study, the combination of certain biomarkers (eotaxin-1, SAA, interleukin [IL]-6, IL-8) was shown to be highly sensitive (90.7\%) and accurate (AUC 0.84), with a PPV of $86.7 \%$ for the diagnosis of endoscopic activity in IBD patients, compared to the widely used clinical indices (Harvey Bradshaw index and Simple Clinical Colitis Activity Index), CRP and FC. Nevertheless, more studies are needed to elucidate the role of this composite biomarker in the assessment of CD activity [75].

Similarly, another composite test, the endoscopic healing index [76], commercially available and known as the PROMETHEUS $^{\circledast}$ Monitr $^{\mathrm{m}}{ }^{\mathrm{m}}$ Crohn's Disease Test, comprises 13 serum proteins (angiopoietin 1 and 2, CRP, SAA1, IL7, extracellular matrix metalloproteinase inducer, matrix metalloproteinases 1, 2, 3 and 9, transforming growth factor $\alpha$, carcinoembryonic antigen-related cell adhesion molecule 1 , and vascular cell adhesion molecule 1) and it was shown to distinguish endoscopic remission with excellent accuracy, in biologic-naïve, early CD patients (AUC 0.962). However, its diagnostic accuracy in chronic biologic experienced patients was shown to be only moderate (AUC 0.693), whilst it was not demonstrated to outperform the diagnostic accuracy of FC in both patient groups.

\section{Cross-sectional imaging modalities}

The introduction of computed tomography (CT) enterography/enteroclysis (CTE/CTEc) and magnetic resonance enterography/enteroclysis (MRE/MREc) has contributed significantly to the diagnosis and evaluation of $\mathrm{CD}$ by allowing the visualization of the entire small intestine. In particular, cross-sectional imaging modalities were demonstrated to be highly reliable, objective and accurate in the classification of CD activity, allowing the evaluation of disease behavior, the identification of disease-related complications and the assessment of treatment response [77].

Both CT and MR require that patients are fasted $4-6 \mathrm{~h}$ prior to the study. Afterwards, 1.5-2 L hyperosmolar oral contrast solution is administered orally to the patient at regular intervals, over a period of approximately 40-60 min. Usually, the solution consists of mannitol, polyethylene glycol or a barium sulfate mixture containing a non-absorbable additive (e.g., sorbitol, polyethylene glycol). Additionally, patients may be given spasmolytics to reduce enteric peristalsis, i.e., hyoscine-Nbutylbromide $\left(\right.$ Buscopan $^{\circledR}$ ) or glucagon $[78,79]$.

Nevertheless, patients may feel discomfort associated with the procedure, as the use of hyperosmolar agents may result in abdominal pain, nausea, vomiting and diarrhea. In addition, the 
use of hyoscine-N-butylbromide is contraindicated in patients with cardiac arrhythmia, narrow angle glaucoma or nonobstructive prostatic hypertrophy, whereas the use of glucagon is contraindicated in patients with pheochromocytoma. Lastly, cross-sectional modality procedures are costly and may require leave from work, whilst the documentation of disease remission and response to treatment may lag compared to endoscopic or clinical remission.

The difference between enterography and enteroclysis is that in the former the contrast agent is administered through the oral route, whereas in the latter, the contrast agent is administered through a nasojejunal tube, resulting in distention of the jejunum.

\section{CTE/CTEC}

CTEc findings were demonstrated to correlate significantly with active mucosal inflammation $(\mathrm{r}=0.7, \mathrm{P}<0.0001)$ [80]. In general, CT studies were shown to have $84.3 \%$ sensitivity and $95.1 \%$ specificity for the diagnosis of inflammatory bowel disease [81]. In particular, the results of one study with CD patients indicated that the performance of CTEc had $89 \%$ sensitivity, $100 \%$ specificity, $100 \% \mathrm{PPV}$, and $89 \% \mathrm{NPV}$ in the discrimination of CD activity [82].

Characteristic CTE/CTEc findings in patients with active $\mathrm{CD}$ are the detection of transmural thickening, hyperdense mucosa, dilatation of the mesenteric veins ("comb sign"), fat wrapping and the presence of lymph nodes [77,83-85]. Despite the comparable diagnostic performance of both modalities, CTE is preferred to CTEc in the investigation of the small bowel, as it does not require the use of a nasojejunal tube to administer the contrast agent and exposes patients to less ionizing radiation. However, in cases where there is a need to examine the proximal small bowel/jejunum, CTEc is preferred.

Lastly, the diagnostic performance of CT enterography in the evaluation of $\mathrm{CD}$ activity is comparable to that of MRE [86-92]; nevertheless, given the concerns regarding patient exposure to ionizing radiation and complications associated with the use of intravenous contrast media [93-96], the use of MRE is preferred.

\section{Low-dose CT}

The development of a new low-dose ionizing radiation CT enterography technique was shown to be highly specific (8497\%) and sensitive (85-94\%) in the detection of CD activity, with patients being exposed to a lower radiation risk compared to that of standard CTE $[97,98]$.

\section{Dual-energy CT (DECT)}

DECT has also been used in CD evaluation. DECT is an iodine-based CT imaging technique that improves tissue characterization by examining tissue behavior with 2 separate
X-ray energy beams. In a small number of studies, DECT was demonstrated to correlate strongly with CDAI ( $r=0.744)$ [99], allowing the accurate discrimination between normal and affected bowel segments (AUC 0.96) [100], and enabling the quantification and objective evaluation of CD activity [101] as well as discrimination between fibrotic and inflammatory lesions [99].

\section{MR enterography}

MR enterography is the main modality for the noninvasive evaluation of the small bowel in CD patients, as it allows highcontrast resolution, multiplanar capability and cine-imaging without exposing patients to ionizing radiation, enabling the objective, accurate and reproducible assessment of CD activity [102]. Moreover, it allows the inflammatory burden to be quantified via specific indices.

The use of contrast agents and bowel distention is crucial for the proper visualization of the bowel wall and the mesenteric veins. Characteristic findings of $\mathrm{CD}$ activity in $\mathrm{MR}$ are submucosal edema, enlarged bowel wall $(>3 \mathrm{~mm})$, lymphadenopathy, fat wrapping and the "comb" sign $[77,103]$.

The overall sensitivity and specificity of MR imaging in CD diagnosis were shown to be $78 \%$ and $85 \%$ respectively, whereas the evaluation of bowel movement may add valuable information for the diagnosis [104]. However, the performance of MRE in the identification of mucosal inflammation in the jejunum is limited by the suboptimal distention of the proximal small bowel [78].

\section{MR indices}

Newly developed MR indices for the quantification of $\mathrm{CD}$ activity, namely the MR index of activity (MaRIA) and the Clermont score, offer reliability and objectivity in the assessment of disease activity [105]. The aforementioned indices are strongly correlated with the CDEIS, demonstrating high diagnostic accuracy in the prediction of mucosal ulceration during endoscopy $(73.9 \%$ and $74.0 \%$, respectively), high specificity ( $82.1 \%$ and $81.3 \%$, respectively) and high NPV ( $82.1 \%$ and $82.4 \%$, respectively) [106]. In particular, the MaRIA index was demonstrated to correlate closely with CDEIS $(\mathrm{r}=0.82, \mathrm{P}<0.001)$, with a high AUC for the discrimination of active disease and the detection of ulcerative lesions $(0.891$ and 0.978 , respectively) [107]. Nevertheless, their complexity means that their use is limited to clinical trials.

\section{Diffusion weighted imaging (DWI) MRI}

DWI is a specific MRI technique, based on the random movement of molecules in fluids inside body tissues [108]. The impedance of water molecule diffusion is affected by the extent of tissue cellularity and the presence of intact cell membranes, and can be quantitatively assessed using the apparent diffusion 
coefficient (ADC) value. The use of DWI alleviates the need for contrast agents during MRI, and it was shown to be a reliable alternative to intravenous gadolinium based MRI in the identification of inflammation, necrosis and malignancy [109]. The accuracy of DWI in the detection of CD activity was shown to be comparable or superior to that of MRE, whilst ADC values demonstrated excellent correlation with the Harvey-Bradshaw index, enabling the quantification of mucosal inflammation with excellent sensitivity and specificity (97.4\% and $99.2 \%$, respectively) [102,110-113].

\section{Ultrasound}

The role of conventional ultrasound in the investigation of $\mathrm{CD}$ is limited. However, the use of high frequency ultrasound probes $(5-17 \mathrm{MHz})$ permits the noninvasive and highly accurate investigation of small-bowel CD, disease-related complications, postoperative recurrence and disease monitoring in patients under treatment, with a diagnostic performance comparable to that of MRE [77,114,115]. CD findings during ultrasonography include the "target sign" (hyperechoic center with a sonolucent $\operatorname{rim}>0.5 \mathrm{~cm}$ ), the failure of loop distention after oral contrast ingestion ("stiff loop"), bowel wall thickness $\geq 3 \mathrm{~mm}$, small bowel dilation $\geq 2.5 \mathrm{~cm}$, small bowel stenosis $<1 \mathrm{~cm}$, presence of fistulas, mesenteric enhancement, lymph nodes, and abscesses [116,117].

Wall thickening and increased vascularity of the thickened segments are the most significant findings in CD assessment, correlating strongly with disease activity [118-121]. In detail, wall thickness $<3 \mathrm{~mm}$ is indicative of endoscopic remission and mucosal healing, with a sensitivity and specificity of $88 \%$ and $93 \%$, respectively $[118,119,121,122]$. However, wall thickness can be associated with both inflammation and fibrosis.

\section{Small intestine contrast ultrasonography (SICUS) and contrast-enhanced ultrasound (CEUS)}

The use of oral and intravenous ultrasound contrast agents has been demonstrated not only to improve image quality and diagnostic performance, but also to facilitate the discrimination between fibrosis and inflammation [77,104,123-125]. In detail, SICUS requires the ingestion of a polyethylene glycol solution, which results in bowel distention and better delineation of the wall layers, while the intravenous application of a contrast agent (CEUS) allows the assessment of tissue perfusion.

The sensitivity of conventional ultrasonography in the identification of small-bowel lesions was demonstrated to range between $57-96 \%$, whereas SICUS was shown to increase sensitivity up to $96-100 \%$ [116]. Furthermore, SICUS detects postsurgical recurrence in $\mathrm{CD}$ patients with a sensitivity and specificity of $99 \%$ and $74 \%$, respectively [126].

Similarly, the detection of hypervascularity and hyperperfusion in intestinal segments with the use of CEUS is strongly associated with disease activity in patients with established CD. Depending on the parameter used for the evaluation of mural micro-vascularity (maximum peak intensity or wash-in slope coefficient), the use of CEUS was shown to result in high sensitivity ( $97 \%$ and $86 \%$, respectively), as well as specificity (83\% for both) [127]. Moreover, CEUS improves the assessment of disease activity [128-130] and allows the accurate prediction of postsurgical recurrence, with studies estimating its sensitivity, specificity and accuracy up to $98 \%, 100 \%$ and $98.3 \%$, respectively [131,132].

\section{Doppler}

In $\mathrm{CD}$ patients the affected wall segment is characterized by hyperemia and vascularization. The aforementioned bowel wall changes can be identified with power or color Doppler, which enables the characterization of the number and diameter of wall vessels [133]. The Limberg score is a semi-quantitative index, developed to assess CD activity. By evaluating vascularization with the help of the Doppler signal in thickened bowel segments ( $>4 \mathrm{~mm}$ ), 4 grades of severity are assigned: a) Grade 1, no vascularization; b) Grade 2, segmental short stretches of vascularity; c) Grade 3, long stretches of vascularity; and d) Grade 4, long stretches of vascularity extending into the mesentery. Although the association of the Limberg score with the histologic activity was shown to be poor $(\kappa=0.4375)$, it demonstrated good correlation with endoscopic findings, in particular the SES-CD score ( $r=0.709)$ [134-137].

Besides the role of Doppler ultrasonography in the evaluation of intestinal lesion vascularity, its use in the assessment of abdominal aortic and superior mesenteric artery (SMA) flow has been proposed as an adjunctive method in the evaluation of CD activity, as hyperdynamic mesenteric circulation is a characteristic of CD [144]. Despite the conflicting results of various studies, SMA measurements were not able to distinguish disease activity among patients, in contrast to aortic measurements, where significant differences correlated with disease activity confirming hyperdynamic circulation in CD [138-144].

\section{Positron emission tomography (PET)}

PET has shown promising results in the assessment of $\mathrm{CD}$ activity, enabling the identification of inflammatory segments in the large and small bowel. In detail, the uptake of ${ }^{18} \mathrm{~F}$-fluorodeoxyglucose from the inflamed bowel segments is proportional to the transmural inflammatory infiltrate, whilst the use of the standardized uptake value in PET enables CD activity grading.

Various studies have indicated that PET has excellent specificity and PPV, as well as good sensitivity and NPV in the prediction of bowel segments with moderate/severe inflammatory activity $(82 \%$ sensitivity, $97 \%$ Specificity, 96\% PPV, 88\% NPV, 91\% accuracy [145]. Nevertheless, the correlation of PET with endoscopic findings/SES-CD was shown to be moderate/low $(r=0.48-0.62)$ [146-148].

Finally, the use of PET technology suffers from significant limitations, as it exposes patients to ionizing radiation and 
it is an expensive modality not widely available, requiring radiopharmaceuticals which are difficult and costly to produce.

In accordance with the joint, evidence-based, 2013 consensus of the European Crohn's and Colitis Organization and the European Society of Gastrointestinal and Abdominal Radiology [77], current evidence cannot support the use of PET in everyday clinical practice.

\section{CD monitoring in pregnant patients}

CD mainly affects patients of reproductive age; thus, it is not uncommon for it to complicate pregnancy in selected cases. Nevertheless, disease activity evaluation in this population can be difficult. Firstly, although endoscopy is considered safe during pregnancy, it should be performed under strong indications and by experienced endoscopists, and it should be postponed until after the third semester when possible [149]. The use of capsule endoscopy is generally not recommended during pregnancy and its use should be restricted to urgent cases that cannot be postponed [150]. Noninvasive monitoring can also be problematic, as biomarkers of inflammation (CRP and erythrocyte sedimentation rate), hemoglobin and serum albumin may be affected in this patient group [151].

Similarly, the results of various studies regarding the role of FC in the evaluation of disease activity in pregnant $\mathrm{CD}$ patients are conflicting; thus, its use cannot be recommended [152]. The use of CT should be avoided in pregnant patients because of concerns about fetal radiation exposure. However, despite the concerns about a possible teratogenic effect of gadolinium contrasts, MRE with an adapted protocol for pregnancy is a reliable and safe imaging modality, as a fetal risk has not yet been proven [152,153]. Similarly, gastrointestinal ultrasonography is an accurate tool in disease monitoring during pregnancy enabling the detection of subclinical inflammation, especially in the majority of patients up to 20 weeks of gestation, where both the colon and the terminal ileum can be assessed with no risks for the fetus [154,155].

\section{Concluding remarks}

The number of noninvasive tools for the evaluation of CD activity is continuously growing. Ileocolonoscopy with biopsies remains the reference standard method for the evaluation of mucosal inflammation and response to treatment. However, the transmural and patchy distribution of the inflamed bowel segments, as well as variations regarding disease location and disease behavior make the assessment of disease activity difficult.

CRP was demonstrated to correlate poorly with endoscopic activity, despite the high specificity of abnormal levels in the prediction of mucosal inflammation. Fecal biomarkers, and especially the most studied FC, have been shown to correlate closely with endoscopic activity, despite its higher diagnostic accuracy in the prediction of colonic mucosa inflammation. In the absence of FC, the detection of fecal hemoglobin can be used as a reliable alternative. Promising innovative biomarkers for the prediction of disease activity are fecal BAFF and SAA, shown to have high diagnostic accuracy in the prediction of $\mathrm{CD}$ activity. The outcome of studies investigating the assessment of mucosal inflammation with the use of biomarker indices did not demonstrate a diagnostic advantage compared to the evaluation with FC alone. MR enterography is highly accurate for the detection of distal small bowel CD activity, whilst it allows the evaluation of transmural inflammation and disease-related complications. However, its diagnostic value decreases in proximal and early CD, whilst it is a costly, timeconsuming procedure, requiring bowel preparation. The use of ultrasonography with contrast agents is gaining interest as a promising, minimally invasive, objective and highly accurate method in the evaluation of CD activity.

Despite the continuous development and progress regarding diagnostic methods for the assessment of CD activity, an ideal diagnostic modality is still lacking. Nevertheless, when endoscopy is not an option for the evaluation of disease activity, physicians should not rely solely on CRP levels and symptoms. In particular, disease activity should be assessed with objective and noninvasive tools, namely fecal biomarkers (e.g., FC), MR enterography and ultrasonography (SICUS or CEUS). The choice of these should be individualized according to the patient's disease phenotype and severity, as well as their expected disease course based on risk factors.

\section{References}

1. Maaser C, Sturm A, Vavricka SR, et al; European Crohn's and Colitis Organisation [ECCO] and the European Society of Gastrointestinal and Abdominal Radiology [ESGAR]. ECCOESGAR Guideline for Diagnostic Assessment in IBD Part 1: Initial diagnosis, monitoring of known IBD, detection of complications. J Crohns Colitis 2019;13:144-164.

2. Best WR, Becktel JM, Singleton JW, Kern F Jr. Development of a Crohn's disease activity index. National Cooperative Crohn's Disease Study. Gastroenterology 1976;70:439-444.

3. Gomollón F, Dignass A, Annese V, et al; ECCO. $3^{\text {rd }}$ European Evidence-based Consensus on the Diagnosis and Management of Crohn's Disease 2016: Part 1: Diagnosis and Medical Management. J Crohns Colitis 2017;11:3-25.

4. Peyrin-Biroulet L, Sandborn W, Sands BE, et al. Selecting therapeutic targets in inflammatory bowel disease (STRIDE): determining therapeutic goals for treat-to-target. $\mathrm{Am} \mathrm{J}$ Gastroenterol 2015;110:1324-1338.

5. Klenske E, Bojarski C, Waldner M, Rath T, Neurath MF, Atreya R. Targeting mucosal healing in Crohn's disease: what the clinician needs to know. Therap Adv Gastroenterol 2019;12:1756284819856865.

6. Mazzuoli S, Guglielmi FW, Antonelli E, Salemme M, Bassotti G, Villanacci V. Definition and evaluation of mucosal healing in clinical practice. Dig Liver Dis 2013;45:969-977.

7. Ungaro RC, Yzet C, Bossuyt P, et al. Deep remission at 1 year prevents progression of early Crohn's disease. Gastroenterology 2020;159:139-147.

8. Peyrin-Biroulet L, Reinisch W, Colombel JF, et al. Clinical disease activity, C-reactive protein normalisation and mucosal healing in Crohn's disease in the SONIC trial. Gut 2014;63:88-95.

9. Shergill AK, Lightdale JR, Bruining DH, et al; American Society for Gastrointestinal Endoscopy Standards of Practice Committee. The role of endoscopy in inflammatory bowel 
disease. Gastrointest Endosc 2015;81:1101-1121.e1-e13.

10. Mary JY, Modigliani R. Development and validation of an endoscopic index of the severity for Crohn's disease: a prospective multicentre study. Groupe d'Etudes Thérapeutiques des Affections Inflammatoires du Tube Digestif (GETAID). Gut 1989;30:983-989.

11. Daperno M, D’Haens G, Van Assche G, et al. Development and validation of a new, simplified endoscopic activity score for Crohn's disease: the SES-CD. Gastrointest Endosc 2004;60:505-512.

12. Rutgeerts P, Geboes K, Vantrappen G, Beyls J, Kerremans R, Hiele M. Predictability of the postoperative course of Crohn's disease. Gastroenterology 1990;99:956-963.

13. Wilkins T, Jarvis K, Patel J. Diagnosis and management of Crohn's disease. Am Fam Physician 2011;84:1365-1375.

14. Cherian S, Singh P. Is routine ileoscopy useful? An observational study of procedure times, diagnostic yield, and learning curve. Am J Gastroenterol 2004;99:2324-2329.

15. Samuel S, Bruining DH, Loftus EV Jr, et al. Endoscopic skipping of the distal terminal ileum in Crohn's disease can lead to negative results from ileocolonoscopy. Clin Gastroenterol Hepatol 2012;10:1253-1259.

16. Kopylov U, Yung DE, Engel T, et al. Diagnostic yield of capsule endoscopy versus magnetic resonance enterography and small bowel contrast ultrasound in the evaluation of small bowel Crohn's disease: systematic review and meta-analysis. Dig Liver Dis 2017;49:854-863.

17. Enns RA, Hookey L, Armstrong D, et al. Clinical practice guidelines for the use of video capsule endoscopy. Gastroenterology 2017; 152:497-514.

18. Pennazio M, Spada C, Eliakim R, et al. Small-bowel capsule endoscopy and device-assisted enteroscopy for diagnosis and treatment of small-bowel disorders: European Society of Gastrointestinal Endoscopy (ESGE) Clinical Guideline. Endoscopy 2015;47:352-376.

19. Kilcoyne A, Kaplan JL, Gee MS. Inflammatory bowel disease imaging: Current practice and future directions. World $J$ Gastroenterol 2016;22:917-932.

20. Colombel JF, Panaccione R, Bossuyt P, et al. Effect of tight control management on Crohn's disease (CALM): a multicentre, randomised, controlled phase 3 trial. Lancet 2017390:2779-2789.

21. Mosli MH, Zou G, Garg SK, et al. C-reactive protein, fecal calprotectin, and stool lactoferrin for detection of endoscopic activity in symptomatic inflammatory bowel disease patients: a systematic review and meta-analysis. Am J Gastroenterol 2015;110:802-819.

22. Kupelian V, Chiu GR, Araujo AB, Williams RE, Clark RV, McKinlay JB. Association of sex hormones and C-reactive protein levels in men. Clin Endocrinol (Oxf) 2010;72:527-533.

23. Sands BE. Biomarkers of inflammation in inflammatory bowel disease. Gastroenterology 2015;149:1275-1285.

24. Ikhtaire S, Shajib MS, Reinisch W, Khan WI. Fecal calprotectin: its scope and utility in the management of inflammatory bowel disease. J Gastroenterol 2016;51:434-446.

25. Reinisch W, Panaccione R, Bossuyt P, et al. Association of biomarker cutoffs and endoscopic outcomes in Crohn's disease: a post hoc analysis from the CALM study. Inflamm Bowel Dis 2020;26:1562-1571.

26. Kopylov U, Yung DE, Engel T, et al. Fecal calprotectin for the prediction of small-bowel Crohn's disease by capsule endoscopy: a systematic review and meta-analysis. Eur J Gastroenterol Hepatol 2016;28:1137-1144.

27. von Roon AC, Karamountzos L, Purkayastha S, et al. Diagnostic precision of fecal calprotectin for inflammatory bowel disease and colorectal malignancy. Am J Gastroenterol 2007;102:803-813.

28. Vernia F, Di Ruscio M, Stefanelli G, Viscido A, Frieri G, Latella G.
Is fecal calprotectin an accurate marker in the management of Crohn's disease? J Gastroenterol Hepatol 2020;35:390-400.

29. Ishihara S, Tada Y, Kawashima K, et al. Serum amyloid A level correlated with endoscopic findings in patients with Crohn's disease-possible biomarker for evaluating mucosal healing. Dig Liver Dis 2018;50:553-558.

30. Yarur AJ, Quintero MA, Jain A, Czul F, Barkin JS, Abreu MT. Serum amyloid a as a surrogate marker for mucosal and histologic inflammation in patients with Crohn's disease. Inflamm Bowel Dis 2017;23:158-164.

31. Palone F, Vitali R, Cucchiara S, et al. Fecal HMGB1 reveals microscopic inflammation in adult and pediatric patients with inflammatory bowel disease in clinical and endoscopic remission. Inflamm Bowel Dis 2016;22:2886-2893.

32. Palone F, Vitali R, Cucchiara S, et al. Role of HMGB1 as a suitable biomarker of subclinical intestinal inflammation and mucosal healing in patients with inflammatory bowel disease. Inflamm Bowel Dis 2014;20:1448-1457.

33. Vitali R, Stronati L, Negroni A, et al. Fecal HMGB1 is a novel marker of intestinal mucosal inflammation in pediatric inflammatory bowel disease. Am J Gastroenterol 2011;106:2029-2040.

34. Somineni HK, Venkateswaran S, Kilaru V, et al. Blood-derived DNA methylation signatures of Crohn's disease and severity of intestinal inflammation. Gastroenterology 2019;156:2254-2265.

35. Nikolaus S, Waetzig GH, Butzin S, et al. Evaluation of interleukin- 6 and its soluble receptor components sIL-6R and sgp130 as markers of inflammation in inflammatory bowel diseases. Int J Colorectal Dis 2018;33:927-936.

36. Kofla-Dlubacz A, Matusiewicz M, Krzystek-Korpacka M, Iwanczak B. Correlation of MMP-3 and MMP-9 with Crohn's disease activity in children. Dig Dis Sci 2012;57:706-712.

37. Kim TJ, Koo JS, Kim SJ, et al. Role of IL-1ra and Granzyme B as biomarkers in active Crohn's disease patients. Biomarkers 2018;23:161-166.

38. Takeyama H, Mizushima T, Iijima H, et al. Platelet activation markers are associated with Crohn's disease activity in patients with low C-reactive protein. Dig Dis Sci 2015;60:3418-3423.

39. Song CS, Park DI, Yoon MY, et al. Association between red cell distribution width and disease activity in patients with inflammatory bowel disease. Dig Dis Sci 2012;57:1033-1038.

40. Tang J, Gao X, Zhi M, et al. Plateletcrit: a sensitive biomarker for evaluating disease activity in Crohn's disease with low hs-CRP. J Dig Dis 2015;16:118-124.

41. Haas SL, Abbatista M, Brade J, Singer MV, Böcker U. Interleukin-18 serum levels in inflammatory bowel diseases: correlation with disease activity and inflammatory markers. Swiss Med Wkly 2009;139:140-145.

42. Czub E, Herzig KH, Szaflarska-Popawska A, et al. Fecal pyruvate kinase: a potential new marker for intestinal inflammation in children with inflammatory bowel disease. Scand J Gastroenterol 2007;42:1147-1150.

43. Agnholt J, Kelsen J, Schack L, Hvas CL, Dahlerup JF, Sørensen ES. Osteopontin, a protein with cytokine-like properties, is associated with inflammation in Crohn's disease. Scand $J$ Immunol 2007;65:453-460.

44. Andus T, Gross V, Caesar I, et al. PMN-elastase in assessment of patients with inflammatory bowel disease. Dig Dis Sci 1993;38:1638-1644.

45. Komine-Aizawa S, Masuda H, Mazaki T, Shiono M, Hayakawa S, Takayama T. Plasma osteopontin predicts inflammatory bowel disease activities. Int Surg 2015;100:38-43.

46. Langhorst J, Elsenbruch S, Koelzer J, Rueffer A, Michalsen A, Dobos GJ. Noninvasive markers in the assessment of intestinal inflammation in inflammatory bowel diseases: performance of fecal lactoferrin, calprotectin, and PMN-elastase, CRP, and 
clinical indices. Am J Gastroenterol 2008;103:162-169.

47. Boschetti G, Garnero P, Moussata D, et al. Accuracies of serum and fecal S100 proteins (calprotectin and calgranulin C) to predict the response to TNF antagonists in patients with Crohn's disease. Inflamm Bowel Dis 2015;21:331-336.

48. Fu Y, Wang L, Xie C, et al. Comparison of non-invasive biomarkers faecal BAFF, calprotectin and FOBT in discriminating IBS from IBD and evaluation of intestinal inflammation. Sci Rep 2017;7:2669.

49. Kato J, Hiraoka S, Nakarai A, Takashima S, Inokuchi T, Ichinose M. Fecal immunochemical test as a biomarker for inflammatory bowel diseases: can it rival fecal calprotectin? Intest Res 2016;14:5-14.

50. Mooiweer E, Fidder HH, Siersema PD, Laheij RJ, Oldenburg B. Fecal hemoglobin and calprotectin are equally effective in identifying patients with inflammatory bowel disease with active endoscopic inflammation. Inflamm Bowel Dis 2014;20:307-314.

51. Xie C, Quan R, Wang L, Chen C, Yan W, Fu Y. Diagnostic value of fecal B cell activating factor in patients with abdominal discomfort. Clin Exp Immunol 2019;198:131-140.

52. Zhang P, Liu X, Guo A, Xiong J, Fu Y, Zou K. B cell-activating factor as a new potential marker in inflammatory bowel disease. Dig Dis Sci 2016;61:2608-2618.

53. Ljung T, Lundberg S, Varsanyi M, et al. Rectal nitric oxide as biomarker in the treatment of inflammatory bowel disease: responders versus nonresponders. World $J$ Gastroenterol 2006;12:3386-3392.

54. Maor I, Rainis T, Lanir A, Lavy A. Adenosine deaminase activity in patients with Crohn's disease: distinction between active and nonactive disease. Eur J Gastroenterol Hepatol 2011;23:598-602.

55. Sajjadi M, Gholamrezaei A, Daryani NE. No association between serum adenosine deaminase activity and disease activity in Crohn's disease. Dig Dis Sci 2015;60:1755-1760.

56. Sipponen T, Haapamäki J, Savilahti E, et al. Fecal calprotectin and S100A12 have low utility in prediction of small bowel Crohn's disease detected by wireless capsule endoscopy. Scand J Gastroenterol 2012;47:778-784.

57. Vrabie R, Kane S. Noninvasive markers of disease activity in inflammatory bowel disease. Gastroenterol Hepatol (N Y) 2014;10:576-584.

58. Wright EK, Kamm MA, De Cruz P, et al. Comparison of fecal inflammatory markers in Crohn's disease. Inflamm Bowel Dis 2016;22:1086-1094.

59. Cracowski JL, Bonaz B, Bessard G, Bessard J, Anglade C, Fournet J. Increased urinary F2-isoprostanes in patients with Crohn's disease. Am J Gastroenterol 2002;97:99-103.

60. Husain N, Tokoro K, Popov JM, Naides SJ, Kwasny MJ, Buchman AL. Neopterin concentration as an index of disease activity in Crohn's disease and ulcerative colitis. J Clin Gastroenterol 2013;47:246-251.

61. Judmaier G, Meyersbach P, Weiss G, Wachter H, Reibnegger G. The role of neopterin in assessing disease activity in Crohn's disease: classification and regression trees. Am J Gastroenterol 1993;88:706-711.

62. Nancey S, Boschetti G, Moussata D, et al. Neopterin is a novel reliable fecal marker as accurate as calprotectin for predicting endoscopic disease activity in patients with inflammatory bowel diseases. Inflamm Bowel Dis 2013;19:1043-1052.

63. Nancey S, Perret-Liaudet A, Moussata D, et al. Urinary neopterin is a valuable tool in monitoring Crohn's disease activity. Inflamm Bowel Dis 2008; 14:1548-1554.

64. Stanke-Labesque F, Pofelski J, Moreau-Gaudry A, Bessard G, Bonaz B. Urinary leukotriene E4 excretion: a biomarker of inflammatory bowel disease activity. Inflamm Bowel Dis 2008;14:769-774.

65. Bourgonje AR, Gabriëls RY, de Borst MH, et al. Serum free thiols are superior to fecal calprotectin in reflecting endoscopic disease activity in inflammatory bowel disease. Antioxidants (Basel) 2019;8:351.

66. Chen W, Paulus B, Shu D, Wilson, Chadwick V. Increased serum levels of eotaxin in patients with inflammatory bowel disease. Scand J Gastroenterol 2001;36:515-520.

67. Mir A, Minguez M, Tatay J, et al. Elevated serum eotaxin levels in patients with inflammatory bowel disease. Am J Gastroenterol 2002;97:1452-1457.

68. Inokuchi T, Kato J, Hiraoka $\mathrm{S}$, et al. Fecal immunochemical test versus fecal calprotectin for prediction of mucosal healing in Crohn's disease. Inflamm Bowel Dis 2016;22:1078-1085.

69. Mackay F, Schneider P, Rennert P, Browning J. BAFF AND APRIL: a tutorial on B cell survival. Annu Rev Immunol 2003;21:231-264.

70. Pyrpasopoulou A, Balaska E, Triantafyllou A, Anyfanti P, Aslanidis S, Douma S. B-cell activating factor levels in rheumatoid arthritis patients in response to treatment with biologics. J Interferon Cytokine Res 2012;32:338-340.

71. Steri M, Orrù V, Idda ML, et al. Overexpression of the cytokine BAFF and autoimmunity risk. N Engl J Med 2017;376:1615-1626.

72. Bartel DP. MicroRNAs: genomics, biogenesis, mechanism, and function. Cell 2004;116:281-297.

73. Cordes F, Brückner M, Lenz P, et al. MicroRNA-320a strengthens intestinal barrier function and follows the course of experimental colitis. Inflamm Bowel Dis 2016;22:2341-2355.

74. Cordes F, Demmig C, Bokemeyer A, et al. MicroRNA-320a monitors intestinal disease activity in patients with inflammatory bowel disease. Clin Transl Gastroenterol 2020;11:e00134.

75. Bourgonje AR, von Martels JZH, Gabriëls RY, et al. A combined set of four serum inflammatory biomarkers reliably predicts endoscopic disease activity in inflammatory bowel disease. Front Med (Lausanne) 2019;6:251.

76. D'Haens G, Kelly O, Battat R, et al. Development and validation of a test to monitor endoscopic activity in patients with Crohn's disease based on serum levels of proteins. Gastroenterology 2020;158:515-526.

77. Panes J, Bouhnik Y, Reinisch W, et al. Imaging techniques for assessment of inflammatory bowel disease: joint ECCO and ESGAR evidence-based consensus guidelines. J Crohns Colitis 2013;7:556-585.

78. Griffin N, Grant LA, Anderson S, Irving P, Sanderson J. Small bowel MR enterography: problem solving in Crohn's disease. Insights Imaging 2012;3:251-263.

79. Ilangovan R, Burling D, George A, Gupta A, Marshall M, Taylor SA. CT enterography: review of technique and practical tips. Br J Radiol 2012;85:876-886.

80. Chiorean MV, Sandrasegaran K, Saxena R, Maglinte DD, Nakeeb A, Johnson CS. Correlation of CT enteroclysis with surgical pathology in Crohn's disease. Am J Gastroenterol 2007;102:2541-2550.

81. Horsthuis K, Bipat S, Bennink RJ, Stoker J. Inflammatory bowel disease diagnosed with US, MR, scintigraphy, and CT: metaanalysis of prospective studies. Radiology 2008;247:64-79.

82. Ozturk E, Cakir O, Mutlu H, et al. Diagnostic value of CTE in patients with Crohn's disease. Clin Imaging 2007;31:185-188.

83. Frager DH, Goldman M, Beneventano TC. Computed tomography in Crohn disease. J Comput Assist Tomogr 1983;7:819-824.

84. Goldberg HI, Gore RM, Margulis AR, Moss AA, Baker EL. Computed tomography in the evaluation of Crohn disease. AJR Am J Roentgenol 1983;140:277-282.

85. Meyers MA, McGuire PV. Spiral CT demonstration of hypervascularity in Crohn disease: "vascular jejunization of the ileum" or the "comb sign". Abdom Imaging 1995;20:327-332.

86. Dave-Verma H, Moore S, Singh A, Martins N, Zawacki J. 
Computed tomographic enterography and enteroclysis: pearls and pitfalls. Curr Probl Diagn Radiol 2008;37:279-287.

87. Fiorino G, Bonifacio C, Peyrin-Biroulet L, et al. Prospective comparison of computed tomography enterography and magnetic resonance enterography for assessment of disease activity and complications in ileocolonic Crohn's disease. Inflamm Bowel Dis 2011;17:1073-1080.

88. Minordi LM, Scaldaferri F, Marra RS, et al. Enterography CT without and with water enema in patients with Crohn's disease: Results from a comparative observational study in comparison with endoscopy. Eur J Radiol 2016;85:404-413.

89. Minordi LM, Vecchioli A, Mirk P, Bonomo L. CT enterography with polyethylene glycol solution vs CT enteroclysis in small bowel disease. Br J Radiol 2011;84:112-119.

90. Qiu Y, Mao R, Chen BL, et al. Systematic review with metaanalysis: magnetic resonance enterography vs. computed tomography enterography for evaluating disease activity in small bowel Crohn's disease. Aliment Pharmacol Ther 2014;40:134-146.

91. Siddiki HA, Fidler JL, Fletcher JG, et al. Prospective comparison of state-of-the-art MR enterography and CT enterography in smallbowel Crohn's disease. AJR Am J Roentgenol 2009;193:113-121.

92. Zimmermann EM, Al-Hawary MM. MRI of the small bowel in patients with Crohn's disease. Curr Opin Gastroenterol 2011;27:132-138.

93. Davenport MS, Cohan RH, Khalatbari S, Ellis JH. The challenges in assessing contrast-induced nephropathy: where are we now? AJR Am J Roentgenol 2014;202:784-789.

94. Maddox TG. Adverse reactions to contrast material: recognition, prevention, and treatment. Am Fam Physician 2002;66:1229-1234.

95. Miglioretti DL, Johnson E, Williams A, et al. The use of computed tomography in pediatrics and the associated radiation exposure and estimated cancer risk. JAMA Pediatr 2013;167:700-707.

96. Smith-Bindman R, Lipson J, Marcus R, et al. Radiation dose associated with common computed tomography examinations and the associated lifetime attributable risk of cancer. Arch Intern Med 2009;169:2078-2086.

97. Ippolito D, Lombardi S, Trattenero C, Franzesi CT, Bonaffini PA, Sironi S. CT enterography: diagnostic value of $4^{\text {th }}$ generation iterative reconstruction algorithm in low dose studies in comparison with standard dose protocol for follow-up of patients with Crohn's disease. Eur J Radiol 2016;85:268-273.

98. Rosenfeld G, Brown J, Vos PM, Leipsic J, Enns R, Bressler B. Prospective comparison of standard- versus low-radiationdose CT enterography for the quantitative assessment of Crohn disease. AJR Am J Roentgenol 2018;210:W54-W62.

99. Kim YS, Kim SH, Ryu HS, Han JK. Iodine quantification on spectral detector-based dual-energy CT enterography: correlation with Crohn's disease activity index and external validation. Korean J Radiol 2018;19:1077-1088.

100. De Kock I, Delrue L, Lecluyse C, Hindryckx P, De Vos M, Villeirs G. Feasibility study using iodine quantification on dualenergy CT enterography to distinguish normal small bowel from active inflammatory Crohn's disease. Acta Radiol 2019;60:679-686.

101. Villanueva Campos AM, Tardáguila de la Fuente G, Utrera Pérez E, Jurado Basildo C, Mera Fernández D, Martínez Rodríguez C. Value of dual-energy CT enterography in the analysis of pathological bowel segments in patients with Crohn's disease. Radiologia (Engl Ed) 2018;60:223-229.

102. Dohan A, Taylor S, Hoeffel C, et al. Diffusion-weighted MRI in Crohn's disease: current status and recommendations. J Magn Reson Imaging 2016;44:1381-1396.

103. Gourtsoyiannis NC, Papanikolaou N, Karantanas A. Magnetic resonance imaging evaluation of small intestinal Crohn's disease. Best Pract Res Clin Gastroenterol 2006;20:137-156.

104. Panés J, Bouzas R, Chaparro M, et al. Systematic review: the use of ultrasonography, computed tomography and magnetic resonance imaging for the diagnosis, assessment of activity and abdominal complications of Crohn's disease. Aliment Pharmacol Ther 2011;34:125-145.

105. Rozendorn N, Amitai MM, Eliakim RA, Kopylov U, Klang E. A review of magnetic resonance enterography-based indices for quantification of Crohn's disease inflammation. Therap Adv Gastroenterol 2018;11:1756284818765956.

106. Buisson A, Pereira B, Goutte M, et al. Magnetic resonance index of activity (MaRIA) and Clermont score are highly and equally effective MRI indices in detecting mucosal healing in Crohn's disease. Dig Liver Dis 2017;49:1211-1217.

107. Rimola J, Rodriguez S, García-Bosch O, et al. Magnetic resonance for assessment of disease activity and severity in ileocolonic Crohn's disease. Gut 2009;58:1113-1120.

108. Hagmann P, Jonasson L, Maeder P, Thiran JP, Wedeen VJ, Meuli R. Understanding diffusion MR imaging techniques: from scalar diffusion-weighted imaging to diffusion tensor imaging and beyond. Radiographics 2006;26 Suppl 1:S205-S223.

109. Baliyan V, Das CJ, Sharma R, Gupta AK. Diffusion weighted imaging: Technique and applications. World J Radiol 2016;8:785-798.

110. Imširović B, Zerem E, Efendić A, Mekić Abazović A, Zerem O, Djedović M. Significance of diffusion weighted imaging (DWI) as an improving factor in contrast enhanced magnetic resonance imaging (MRI) enterography in evaluation of patients with Crohn's disease. Med Glas (Zenica) 2018;15:145-151.

111. Masselli G, De Vincentiis C, Aloi M, et al. Detection of Crohn's disease with diffusion images versus contrast-enhanced images in pediatric using MR enterography with histopathological correlation. Radiol Med 2019;124:1306-1314.

112. Seo N, Park SH, Kim KJ, et al. MR enterography for the evaluation of small-bowel inflammation in Crohn disease by using diffusionweighted imaging without intravenous contrast material: a prospective noninferiority study. Radiology 2016;278:762-772.

113. Stanescu-Siegmund N, Nimsch Y, Wunderlich AP, et al. Quantification of inflammatory activity in patients with Crohn's disease using diffusion weighted imaging (DWI) in MR enteroclysis and MR enterography. Acta Radiol 2017;58:264-271.

114. Kucharzik T, Maaser C. Intestinal ultrasound and management of small bowel Crohn's disease. Therap Adv Gastroenterol 2018;11:1756284818771367.

115. Yuksel I, Kilincalp S, Coskun Y, Akinci H, Hamamci M, Alkan A. Diagnostic accuracy of intestinal ultrasound and magnetic resonance enterography for the detection of endoscopy-based disease activity in ileocolonic Crohn's disease. Eur J Gastroenterol Hepatol 2019;31:809-816.

116. Mocci G, Migaleddu V, Cabras F, et al. SICUS and CEUS imaging in Crohn's disease: an update. J Ultrasound 2017;20:1-9.

117. Pallotta N, Tomei E, Viscido A, et al. Small intestine contrast ultrasonography: an alternative to radiology in the assessment of small bowel disease. Inflamm Bowel Dis 2005;11:146-153.

118. Haber HP, Busch A, Ziebach R, Stern M. Bowel wall thickness measured by ultrasound as a marker of Crohn's disease activity in children. Lancet 2000;355:1239-1240.

119. Maconi G, Parente F, Bollani S, Cesana B, Bianchi Porro G. Abdominal ultrasound in the assessment of extent and activity of Crohn's disease: clinical significance and implication of bowel wall thickening. Am J Gastroenterol 1996;91:1604-1609.

120. Strobel D, Goertz RS, Bernatik T. Diagnostics in inflammatory bowel disease: ultrasound. World J Gastroenterol 2011;17:3192-3197.

121. Wale A, Pilcher J. Current role of ultrasound in small bowel imaging. Semin Ultrasound CT MR 2016;37:301-312.

122. Moreno N, Ripollés T, Paredes JM, et al. Usefulness of abdominal ultrasonography in the analysis of endoscopic activity in 
patients with Crohn's disease: changes following treatment with immunomodulators and/or anti-TNF antibodies. J Crohns Colitis 2014;8:1079-1087.

123. Kumar S, Hakim A, Alexakis C, et al. Small intestinal contrast ultrasonography for the detection of small bowel complications in Crohn's disease: correlation with intraoperative findings and magnetic resonance enterography. J Gastroenterol Hepatol 2015;30:86-91.

124. Pallotta N, Vincoli G, Montesani C, et al. Small intestine contrast ultrasonography (SICUS) for the detection of small bowel complications in Crohn's disease: a prospective comparative study versus intraoperative findings. Inflamm Bowel Dis 2012;18:74-84.

125. Ripollés T, Rausell N, Paredes JM, Grau E, Martínez MJ, Vizuete J. Effectiveness of contrast-enhanced ultrasound for characterisation of intestinal inflammation in Crohn's disease: a comparison with surgical histopathology analysis. J Crohns Colitis 2013;7:120-128.

126. Rispo A, Imperatore N, Testa A, et al. Diagnostic accuracy of ultrasonography in the detection of postsurgical recurrence in Crohn's disease: a systematic review with meta-analysis. Inflamm Bowel Dis 2018;24:977-988.

127. De Franco A, Di Veronica A, Armuzzi A, et al. Ileal Crohn disease: mural microvascularity quantified with contrast-enhanced US correlates with disease activity. Radiology 2012;262:680-688.

128. Girlich C, Jung EM, Huber E, et al. Comparison between preoperative quantitative assessment of bowel wall vascularization by contrast-enhanced ultrasound and operative macroscopic findings and results of histopathological scoring in Crohn's disease. Ultraschall Med 2011;32:154-159.

129. Socaciu M, Ciobanu L, Diaconu B, Hagiu C, Seicean A, Badea R. Non-invasive assessment of inflammation and treatment response in patients with Crohn's disease and ulcerative colitis using contrast-enhanced ultrasonography quantification. J Gastrointestin Liver Dis 2015;24:457-465.

130. Wilkens R, Hagemann-Madsen RH, Peters DA, et al. Validity of contrast-enhanced ultrasonography and dynamic contrastenhanced MR enterography in the assessment of transmural activity and fibrosis in Crohn's disease. J Crohns Colitis 2018; 12:48-56

131. Martínez MJ, Ripollés T, Paredes JM, Moreno-Osset E, Pazos JM, Blanc E. Intravenous contrast-enhanced ultrasound for assessing and grading postoperative recurrence of Crohn's disease. Dig Dis Sci 2019;64:1640-1650.

132. Paredes JM, Ripollés T, Cortés X, et al. Contrast-enhanced ultrasonography: usefulness in the assessment of postoperative recurrence of Crohn's disease. J Crohns Colitis 2013;7:192-201.

133. Esteban JM, Maldonado L, Sanchiz V, Minguez M, Benages A. Activity of Crohn's disease assessed by colour Doppler ultrasound analysis of the affected loops. Eur Radiol 2001;11:1423-1428.

134. Limberg B. [Diagnosis of chronic inflammatory bowel disease by ultrasonography]. Z Gastroenterol 1999;37:495-508.

135. Neye H, Voderholzer W, Rickes S, Weber J, Wermke W, Lochs H. Evaluation of criteria for the activity of Crohn's disease by power Doppler sonography. Dig Dis 2004;22:67-72.

136. Sasaki T, Kunisaki R, Kinoshita H, et al. Use of color Doppler ultrasonography for evaluating vascularity of small intestinal lesions in Crohn's disease: correlation with endoscopic and surgical macroscopic findings. Scand J Gastroenterol 2014;49:295-301.

137. Bots S, Nylund K, Löwenberg M, Gecse K, Gilja OH, D’Haens G. Ultrasound for assessing disease activity in IBD patients: a systematic review of activity scores. J Crohns Colitis 2018;12:920-929.

138. Andrade TG, Fogaça HS, Elia CC, Pitrowsky MT, Souza HS. Crohn's disease activity assessed by Doppler sonography: the role of aortic flow parameters. Clinics (Sao Paulo) 2013;68:457-462.

139. Byrne MF, Farrell MA, Abass S, et al. Assessment of Crohn's disease activity by Doppler sonography of the superior mesenteric artery, clinical evaluation and the Crohn's disease activity index: a prospective study. Clin Radiol 2001;56:973-978.

140. Karoui S, Nouira K, Serghini M, et al. Assessment of activity of Crohn's disease by Doppler sonography of superior mesenteric artery flow. J Crohns Colitis 2010;4:334-340.

141. Ludwig D, Wiener S, Brüning A, Schwarting K, Jantschek G, Stange EF. Mesenteric blood flow is related to disease activity and risk of relapse in Crohn's disease: a prospective follow-up study. Am J Gastroenterol 1999;94:2942-2950.

142. Maconi G, Asthana AK, Bolzacchini E, et al. Splanchnic hemodynamics and intestinal vascularity in Crohn's disease: an in vivo evaluation using Doppler and contrast-enhanced ultrasound and biochemical parameters. Ultrasound Med Biol 2016;42:150-158.

143. Sjekavica I, Barbarić-Babić V, Krznarić Z, Molnar M, CukovićCavka S, Stern-Padovan R. Assessment of Crohn's disease activity by Doppler ultrasound of superior mesenteric artery and mural arteries in thickened bowel wall: cross-sectional study. Croat Med J 2007;48:822-830.

144. van Oostayen JA, Wasser MN, van Hogezand RA, et al. Doppler sonography evaluation of superior mesenteric artery flow to assess Crohn's disease activity: correlation with clinical evaluation, Crohn's disease activity index, and alpha 1-antitrypsin clearance in feces. AJR Am J Roentgenol 1997;168:429-433.

145. Däbritz J, Jasper N, Loeffler M, Weckesser M, Foell D. Noninvasive assessment of pediatric inflammatory bowel disease with ${ }^{18} \mathrm{~F}$-fluorodeoxyglucose-positron emission tomography and computed tomography. Eur J Gastroenterol Hepatol 2011;23:81-89.

146. Louis E, Ancion G, Colard A, Spote V, Belaiche J, Hustinx R. Noninvasive assessment of Crohn's disease intestinal lesions with (18)F-FDG PET/CT. J Nucl Med 2007;48:1053-1059.

147. Saboury B, Salavati A, Brothers A, et al. FDG PET/CT in Crohn's disease: correlation of quantitative FDG PET/CT parameters with clinical and endoscopic surrogate markers of disease activity. Eur J Nucl Med Mol Imaging 2014;41:605-614.

148. Shyn PB, Mortele KJ, Britz-Cunningham SH, et al. Low-dose 18F-FDG PET/CT enterography: improving on CT enterography assessment of patients with Crohn disease. J Nucl Med 2010;51:1841-1848.

149. Restellini S, Biedermann L, Hruz P, et al; on behalf of Swiss IBDnet, an official working group of the Swiss Society of Gastroenterology. Update on the management of inflammatory bowel disease during pregnancy and breastfeeding. Digestion 2020;101 Suppl 1:27-42.

150. Bandorski D, Kurniawan N, Baltes P, et al. Contraindications for video capsule endoscopy. World $J$ Gastroenterol 2016;22:9898-9908.

151. Schulze H, Esters P, Dignass A. Review article: the management of Crohn's disease and ulcerative colitis during pregnancy and lactation. Aliment Pharmacol Ther 2014;40:991-1008.

152. Choden T, Mandaliya R, Charabaty A, Mattar MC. Monitoring inflammatory bowel disease during pregnancy: Current literature and future challenges. World J Gastrointest Pharmacol Ther 2018;9:1-7.

153. Stern MD, Kopylov U, Ben-Horin S, Apter S, Amitai MM. Magnetic resonance enterography in pregnant women with Crohn's disease: case series and literature review. BMC Gastroenterol 2014;14:146.

154. Flanagan E, Wright EK, Begun J, et al. Monitoring inflammatory bowel disease in pregnancy using gastrointestinal ultrasonography. J Crohns Colitis 2020;14:1405-1412.

155. Leung Y, Shim HH, Wilkens R, et al. The role of bowel ultrasound in detecting subclinical inflammation in pregnant women with Crohn's disease. J Can Assoc Gastroenterol 2019;2:153-160. 